\title{
BIBLIA E ARQUEOLOGIA: A CONTRIBUIÇÃO DA BIBLIOTECA COPTA DE NAG HAMMADI PARA O ESTUDO DO CRISTIANISMO
}

\author{
Maria Aparecida de Andrade Almeida ${ }^{1}$
}

\begin{abstract}
Resumo: Em 1945, uma coleção de manuscritos em língua copta foi encontrada por camponeses egípcios, próxima à cidade de Nag Hammadi. Esta coleção contendo treze códices feitos de papiro e protegidos com couro recebeu o nome de Biblioteca Copta Nag Hammadi. Uma importante descoberta para a língua copta, para a história da filosofia antiga e para o cristianismo, pois esta biblioteca abre-nos uma nova janela sobre o período formativo do cristianismo. As descobertas de 1945 deram início a uma nova era na pesquisa de manifestações do cristianismo primitivo, por conter tratados de teologia sistemática, obras exegéticas, epístolas, apocalipses, biografias e diários de viagem, relatos apócrifos da paixão de Jesus e códigos morais de várias fontes e ideologias. O objetivo do mini-curso "Bíblia e Arqueologia" foi apresentar aos participantes a história da descoberta desta biblioteca, como ela foi formada, o avanço das pesquisas e a grande contribuição que ela traz para o estudo do Cristianismo.
\end{abstract}

Palavras Chave: Bíblia, Gnosticismo, Copta, Cristianismo primitivo, Nag Hammadi.

\section{BIBLE AND ARCHAEOLOGY: THE CONTRIBUTION OF THE COPTIC NAG HAMMADI LIBRARY TO THE STUDY OF CHRISTIANITY}

\begin{abstract}
In 1945, a manuscript collection in Coptic language was found by Egyptian peasants near the Egyptian town of Nag Hammadi. This collection containing thirteen papyrus codices (each volume bound and enveloped in leather) was named the Coptic Nag Hammadi Library. An important discovery for the Coptic language, for the history of ancient philosophy and Christianity, since this library opens a new window into the formative period of Christianity. The 1945 findings defined a new era in Early Christianity research, for providing a body of work on systematic theology, biblical exegesis and revelations, Epistles, biographies and travel diaries, apocryphal accounts of The Passion of Jesus and moral codes from several sources and ideologies. The aim of the short course "Bible and Archaeology" was to introduce participants

\footnotetext{
${ }^{1}$ Pós-Doutorado em História e Arqueologia pela Universidade Estadual de Campinas (2014/Atual); Doutora e Mestre em Ciências da Religião/ Literatura e Religião no Mundo Bíblico pela Universidade Metodista de São Paulo (2006/20012); Bacharel em Teologia pela Faculdade Dehoniana de Taubaté (2002/2005); Tem experiência nas áreas Teológica e Bíblica, atuando nos campos Educacional e Pastoral; Integrante do Grupo de Pesquisa Arqueologia da Repressão e da Resistência; Bolsista FAPESP; Email: mcidalmeida@hotmail.com.
}

\begin{tabular}{|l|l|l|l|l|l|l|}
\hline (C) Rev. Arqueologia Pública & Campinas, SP & v.9 & No.(11) & p.43-57 & suplemento & ISSN 2237-8294 \\
\hline
\end{tabular}


to such library's history of discovery, its build process, research breakthroughs and its great contribution to the study of Christianity.

Keywords: Bible, Gnosticism, Coptic, early Christianity, Nag Hammadi.

\section{Biblia y arqueología: la contribución de la biblioteca Copta de Nag Hammadi para el estudio del cristianismo}

Resumen: En 1945, una colección de manuscritos en el idioma copto fue encontrada por campesinos egipcios, prójimo a la ciudad de Nag Hammadi. Esta colección conteniendo trece códices hechos de papiro y protegidos por cuero ha recibido este nombre desde la Biblioteca Nag Hammadi. Fue una importante descubierta para el idioma copto, para la historia de la antigua filosofía y para el cristianismo. Estas descubiertas del 1945 dieron inicio a una nueva era en la investigación de manifestaciones del cristianismo primitivo, por contener tratados de teología sistemática, obras exegéticas, epístolas, apocalipsis, biografías y diarios de viaje, relatos apócrifos de la pasión de Jesús y códigos morales de varias fuentes e ideologías. El objetivo del mini-curso "Biblia y Arqueología" fue presentar los participantes a la historia de la descubierta de esta biblioteca, como ella fue conformada, el avance de las investigaciones y la contribución que esta trae para el estudio del Cristianismo.

Palabras clave: Biblia, el gnosticismo, el copto, el cristianismo primitivo, Nag Hammadi.

\section{Introdução}

Os séculos XIX e XX presenciaram muitas descobertas arqueológicas importantes para o estudo das religiões da antiguidade, sobretudo o judaísmo, o cristianismo e outras crenças ligadas direta ou indiretamente a estas, como o gnosticismo e o maniqueísmo. Pode-se presenciar, portanto, um grande aumento no interesse pelo estudo do cristianismo primitivo. Desde a segunda metade do século XIX, o volume de edições e traduções de fontes antigas relativas aos estudos de religião aumentou consideravelmente (CHAVES, 2011:1). Neste sentido, a História e a Arqueologia estão intrinsecamente ligadas. Daí tem-se que admitir o fato de que a relação entre as disciplinas História e Arqueologia tem sofrido grandes transformações nos últimos anos.

( Rev. Arqueologia Pública

Campinas, SP

v.9 No.(11) p.43-57 suplemento ISSN 2237-8294 
Conforme indicam os estudos de P. Funari, com o surgimento de movimentos questionadores dessa condição, as Ciências Humanas e Sociais experimentaram uma sensível transformação. Os modelos explicativos que entendiam a sociedade e cultura como realidades homogêneas deram lugar a uma explicação mais plausível dessas realidades considerando sua pluralidade e, por isso mesmo, suas contradições e contrastes (FUNARI, 2007:42).

Três grandes descobertas arqueológicas de fontes primárias impulsionaram a intensificação das pesquisas na área histórica e arqueológica: Uma é sem dúvida a descoberta dos papiros de Oxiríncos, feita por dois arqueólogos britânicos, Grenfell e Hunt, no final do século XIX, na região central do Egito, próximo à margem leste do Nilo. Esta descoberta trouxe ao conhecimento dos estudiosos textos gregos de várias naturezas, dentre eles alguns textos cristãos.

Outra descoberta aconteceu no sul do Egito, próximo à cidade moderna de Nag Hammadi no ano de 1945. Porém, o mundo estava interessado nos momentos finais da Segunda Grande Guerra e em suas consequências, não foi dada muita importância à descoberta. No entanto, nos anos decorrentes os especialistas começaram a tomar contato com os textos, apesar da relativa demora na publicação.

E ainda, a descoberta dos Manuscritos do Mar Morto na Palestina, no ano de 1948. Tratava-se de milhares de fragmentos de textos aramaicos e hebraicos. Entre os escritos descobertos havia textos bíblicos e também textos sectários que revelam certa diversidade no judaísmo antigo. Os textos de Qumran ficaram conhecidos pelo nome de Manuscritos do Mar Morto e propiciaram uma grande quantidade de fontes para o estudo do judaísmo antigo e ainda para o entendimento de textos cristãos com motivações e background judaicos, como o Apocalipse, por exemplo.

No caso específico dos códices de Nag Hammadi, a tendência de pesquisar os textos e evidências arqueológicas para comprovar interpretações de textos sagrados deve ser superada por pesquisas mais independentes, que associam as disciplinas destacando as contribuições e respeitando os limites de cada uma, objetivando resultados integrados. Como essas considerações mostram, as novas perspectivas giram em torno das relações interdisciplinares, especialmente a História, a Arqueologia e as Ciências da Religião e também da relação entre cultura material e documentação escrita.

(C) Rev. Arqueologia Pública

Campinas, SP

v.9 No.(11) p.43-57 suplemento ISSN 2237-8294 


\section{A Biblioteca Copta de Nag Hammadi}

Em dezembro de 1945, próximo à cidade de Nag Hammadi, à margem leste do Nilo, no alto Egito, uma coleção de manuscritos em língua copta foi encontrada por dois camponeses egípcios. Eles estavam procurando um tipo de fertilizante natural e começaram a cavar em torno de uma pedra. Sem querer, encontraram um jarro de barro selado na parte superior. Um dos camponeses, chamado Muhammad'Ali al-Sammãn quebrou o jarro com uma picareta, na esperança de encontrar algo valioso, talvez um tesouro. Deve ter ficado um tanto quanto decepcionado ao ver que, em vez de ouro, no jarro só havia fragmentos de papiros. Sem se dar conta havia descoberto uma coleção contendo treze códices feitos de papiro e cobertos com couro, que recebeu o nome de Biblioteca Copta de Nag Hammadí (ROBINSON, 2006:30-40).

A interpretação destes textos é particularmente difícil, porque sabe-se pouco sobre seus autores ou sobre os locais, datas e circunstâncias em que foram escritos em grego, em seguida, traduzidos para o copta, a língua vernácula do Egito na antiguidade tardia, e finalmente, copiados para os códices redescobertos em 1945. Esforços de pesquisa elaborada têm permitido estudiosos situá-los em seu contexto e extrair deles uma grande quantidade de informações. O conteúdo desta biblioteca, a edição crítica, a tradução para línguas modernas, e o estudo destes textos, embora ainda numa fase, pode-se dizer inicial, abre-nos novas perspectivas por trazerem elementos que circularam no contexto das comunidades primitivas e influenciaram na forma de vida do cristianismo em seu período de formação (PAINCHAUD, 2005:9-10). Como previra J. Doresse: "as descobertas da BCNH em 1945 deram início a uma nova era na pesquisa" (DORESSE, 1958:142-145).

A BCNH constitui hoje, inegavelmente, a fonte mais importante do movimento gnóstico cristão que tanto impacto teve no pensamento religioso e filosófico na bacia do Mediterrâneo, dos séculos I ao IV d.C. Os seus "autores" diziam-se portadores dos ensinamentos secretos e esotéricos revelados (ou des-velados) por Jesus, o Cristo. Ao contactar com estes textos percebe-se a riqueza espiritual e filosófica do cristianismo dos primeiros séculos. Esta versão gnóstica do cristianismo foi rejeitada pela corrente ortodoxa (ou o que desembocará no que é m hoje a ortodoxia). O estudo sobre o gnosticismo tem avançado muito desde a descoberta e a tradução dos manuscritos de Nag Hammadi que lançam alguma luz sobre alguns dos

\footnotetext{
${ }^{2}$ Daqui para frente usaremos a sigla BCNH para Biblioteca Copta de Nag Hammadi.
}

(C) Rev. Arqueologia Pública

Campinas, SP

v.9 No.(11) p.43-57 suplemento ISSN 2237-8294 
comentários mais intrigantes feitos por Plotino e Porfírio sobre os gnósticos (PAINCHAUD, 2005:9-10).

A tradução e compreensão dos textos são dificultadas pelo estado fragmentado e precário do material que contém lacunas e trechos não legíveis. Entretanto, os especialistas tentaram reconstruir boa parte do texto perdido através da comparação com outros trechos de padrão e características semelhantes, tendo em vista as constantes repetições de frases e expressões.

Houve três tentativas para numeração dos códices da Biblioteca: a primeira numeração foi feita por $\mathrm{H}$. Puech e segue a ordem em que se teve notícia dos códices; (PUECH, 1950:100-110). A segunda foi feita por J. Doresse, que realizou sua numeração a partir da data estimada dos estilos de caligrafia nos códices (DORESSE, 1958:142-145) e a terceira foi feita por P. Labib, que fez a numeração oficial para o Museu Copta do Cairo, sendo bem aceita pelos estudiosos atualmente. De acordo com o projeto de edição da BCNH (Université Laval - Quebec, Canadá), ${ }^{3}$ assim como o NT, a BCNH contém vários gêneros literários, incluindo evangelhos, obras apocalípticas, obras místicas e vidas dos apóstolos:

Codex I: $A$ oração do apóstolo Paulo; $O$ apócrifo de Tiago; $O$ evangelho da verdade (Este texto não possui título no manuscrito. Recebeu este nome dos estudiosos devido a sua frase inicial: $O$ evangelho da verdade é alegria). $O$ tratado sobre a ressurreição; $O$ tratado tripartido. Codex II: $O$ apócrifo de João (Este texto tem outras recensões em outros códices de Nag Hammadi e uma outra no Codex Berlim (BC 8502, 2)); O evangelho de Tomé; $O$ evangelho de Felipe; $A$ hipóstase dos arcontes; $O$ escrito sem título (Como o próprio nome sugere, este escrito não possui título no manuscrito. O título é proposto pelos estudiosos. Os estudiosos de língua inglesa também se referem

${ }^{3}$ Fundada em 1977 pelos professores Jacques É. Ménard da Université des Sciences Humaines de Strasbourg, Gagné Hervé e Michel Roberge da Université Laval, a Bibliothèque copte de Nag Hammadi está atualmente sob a direção de Louis Painchaud, Wolf-Peter Funk, e Paul-Hubert Poirier. Além dos acima mencionados, o comitê editorial é composto por Bernard Barc, Régine Charron, Jean-Pierre Mahé, Pasquier Anne, Michel Roberge, e D. John Turner. A coleção é publicada conjuntamente por Les Presses de l'Université Laval (Québec) e Les Éditions Peeters (Louvain-Paris). Ele consiste em três séries: Études, Textes e Concordâncias, cf. http://www.naghammadi.org/publications/serie textes.aspx. Acesso em 28 jan. de 2011.

(C) Rev. Arqueologia Pública

Campinas, SP

v.9 No.(11) p.43-57 suplemento ISSN 2237-8294 
a este texto como On the origin of the world); $A$ exegese da alma; $O$ livro de Tomé (Devido a um erro de tradução, este texto é também conhecido como O livro de Tomé, o atleta. No entanto, a palavra atleta não pertence ao título do texto em questão. Trata-se da primeira palavra do cólofon do codex II. Cólofon é uma espécie de nota colocada pelo escriba ou copista ao final do manuscrito). Codex III: $O$ apócrifo de João (versão breve); O livro sagrado do Grande Espírito invisível (Também conhecido como Gospel of the Egyptians); Eugnostos, o bem-aventurado; A sabedoria de Jesus Cristo; O diálogo do Salvador. Codex IV: O apócrifo de João (versão longa); O livro sagrado do Grande Espírito invisível. Codex V: Eugnostos, o bemaventurado; $O$ apocalipse de Paulo; $O$ (primeiro) apocalipse de Tiago (Existem dois textos com o mesmo título no codex V: $O$ apocalipse de Tiago. Os estudiosos, portanto, resolveram nomeá-los como Primeiro e Segundo, de acordo com a disposição no codex V, para assim diferenciá-los); $O$ (segundo) apocalipse de Tiago; $O$ apocalipse de Adão. Codex VI: Os atos de Pedro e dos doze apóstolos; O trovão, mente perfeita; $O$ autêntico logos; $O$ conceito de nosso grande poder; $A$ república de Platão (588A-589B); $A$ Hebdômada e a Enêada; $A$ oração de ação de graças; Alcelpius. Codex VII: A paráfrase de Sem; O segundo tratado do grande Set; $O$ apocalipse de Pedro; Os ensinamentos de Silvano; Os três marcos de Set. Codex VIII: Zostrianos; A carta de Pedro a Felipe. Codex IX: Melquisedeque; Nórea, O testemunho verdadeiro. Codex X: Marsánes. Codex XI: $A$ interpretação da gnose; $A$ exposição valentiniana; Allógenes; ypsifrone. Codex XII: As sentenças de Sextus; $O$ evangelho da verdade (Trata-se de uma versão diferente do texto de mesmo nome do codex I. Porém, esta versão não está completa. São apenas fragmentos). Codex XIII: Protenoia trimórfica (CHAVES, 2011).

\section{Sobre o atual estágio da pesquisa}

Boa parte da literatura encontrada na BCNH é nitidamente cristã. Certos textos, contudo, mostram pouca ou nenhuma influência cristã; alguns provêm de fontes ditas pagãs, e outros fazem uso extenso de tradições judaicas. Os papiros estavam escritos em copta, uma língua nativa do Egito na época romana e que hoje é usada apenas como língua litúrgica.

( Rev. Arqueologia Pública

Campinas, SP

v.9 No.(11) p.43-57 suplemento ISSN 2237-8294 
Quanto às datas dos textos originais, os estudiosos divergem: alguns não poderiam ser posteriores a 120 ou 150 d.C, pois Irineu, o bispo ortodoxo de Lyon, escrevendo por volta de 180 d.C, declarou que "os hereges dizem possuir mais evangelhos do que realmente existem", e lastima que nessa época esses escritos tivessem atingido grande circulação - da Gália a Roma, da Grécia à Ásia Menor. O pesquisador G. Quispel e seus colaboradores sugerem que os originais sejam datados por volta do ano 140 d.C; já o prof. H. Koester, de Harvard, sugeriu que um dos manuscritos, $O$ Evangelho de Tomé, talvez inclua algumas tradições ainda mais antigas que os evangelhos do Novo Testamento, contemporâneas ou anteriores a Marcos, Mateus, Lucas e João que foram escritos por volta de 50 a 100 d.C. (KOESTER, 2005:167).

No que diz respeito à publicação dos textos da $\mathrm{BCNH}^{4}$, segundo Chaves é importante citar a história política e social do Egito contemporâneo, sobretudo no final dos anos 40 e anos 50. Em 1947, o Egito enfrenta Israel em uma guerra; em 1952, o país passa por uma revolução que dura até o ano de 1954, com a abdicação do rei Faruk, e a proclamação da Republica Egípcia; ainda, em 1956, o país enfrenta Israel em uma nova guerra. Todos estes eventos retardaram de certa maneira a publicação dos textos. É o caso, por exemplo, do documento conhecido como Evangelho da verdade, que foi publicado em 1956 por M. Malinine, H.-Ch. Puech e G. Quispel; e do Evangelho de Tomé, publicado em 1959. No entanto, somente em 1961, iniciou-se um esforço para a publicação completa dos textos da BCNH. H.-Ch. Puech e A. Guillaumont sugeriram à UNESCO que financiasse a publicação completa dos textos. Então entrou em cena um estudioso muito importante para a história da pesquisa de Nag Hammadi, J. Robinson. ${ }^{5}$ Ele encarregou-se de criar o Comitê internacional dos códices de Nag Hammadi. Sob o patronato da UNESCO, e tendo como editor chefe J.

\footnotetext{
${ }^{4}$ As edições críticas em inglês foram publicadas separadamente na coleção "Nag Hammadi Studies" ao longo dos anos 70, 80 e 90 e depois reimpressas juntas em 5 volumes nos anos 2000, com o nome de "The Coptic Gnostic Library". Para conhecer a lista atual de textos traduzidos e todas as edições críticas já publicadas pela Université Laval e aquelas que vão ser publicadas, Cf. http://www.naghammadi.org/publications/serie textes.aspx http://www.naghammadi.org/traductions/traductions.aspx. Acesso em 11 nov. de 2013.

5 J. Robinson foi o organizador da primeira tradução completa dos textos de Nag Hammadi, em 1977, feita por pesquisadores do Instituto para a antiguidade e cristianismo da Claremont Graduate School, na Califórnia. A edição recebeu o nome de The Nag Hammadi Library in English, e foi publicada contendo as traduções em inglês dos textos de Nag Hammadi e de mais dois textos ditos gnósticos do Codex de Berlim, o Evangelho de Maria (BC 8502, 1) e Os atos de Pedro (BC 85502, 4), juntamente com breves introduções a cada texto. Esta tradução prestou enormes serviços, pois, além de ser a primeira tradução de todos os textos de Nag Hammadi, tornou tais textos acessíveis não só aos estudiosos, mas ao grande público em geral.
}

(C) Rev. Arqueologia Pública

\begin{tabular}{l|l|l} 
Campinas, SP & v.9 & No.(11)
\end{tabular} p.43-57 suplemento ISSN 2237-8294 
Robinson, este comitê publicou entre os anos de 1972 e 1984 doze volumes com as fotos das páginas de papiros, os fragmentos e as coberturas de couro dos códices de Nag Hammadi. Esta edição é conhecida como a edição fac-símile de Nag Hammadi (CHAVES, 2011:20-21).

Existem atualmente três edições criticas com tradução dos textos de Nag Hammadi. Uma delas realizada pelo mesmo grupo da Califórnia que publicou The Nag Hammadi Library in English e se chama The Coptic Gnostic Library, e foi lançada em cinco volumes, em uma coleção com o título de Nag Hammadi Studies. Uma nova edição em inglês foi preparada sob a direção de Marvin Meyer. A ideia foi tornar acessível em língua inglesa, novas traduções atualizadas dos textos de Nag Hammadi, com aparatos críticos e notas, igualmente atualizados e em consonância com as evoluções da coptologia nos últimos 30 anos. Esta edição, preparada pela editora Harper San Francisco, conta com a colaboração dos pesquisadores canadenses e alemães. As outras duas edições críticas dos textos de $\mathrm{Nag}$ Hammadi foram realizadas em Berlim, Alemanha e em Québec, Canadá. A edição alemã foi publicada com o título de Berliner Arbeitskreiz für Koptisch-gnostiche Schriften na coleção Texte und Untersuchungen zur Geschichte der altchristlichen Literatur. E a tradução integral dos textos de Nag Hammadi em alemão está disponível com o título de Nag Hammadi Deutsch.

A edição crítica publicada pela Universidade Laval em Québec começou a ser realizada no fim da década de 70 com o título de Bibliothèque copte de Nag Hammadi. Tratase de uma coleção com três secções: "textos", "estudos" e "concordância". A secção "textos" comporta a tradução em francês, juntamente com o texto copta editado de acordo com a disposição das linhas no manuscrito de Nag Hammadi, bem como notas, aparato crítico, índex de palavras coptas e gregas e uma introdução bem desenvolvida, juntamente com um comentário extenso do texto. Esta secção já publicou trinta e quatro volumes, tendo sido o último a Interpretação da Gnose (CHAVES, 2011:23).

Nos últimos 25 anos muitos pesquisadores estiveram em Quebec e contribuíram diretamente para as três seções, "Textos", "Educação" e "Concordâncias" na coleção "Biblioteca copta de Nag Hammadl, publicado conjuntamente pela Presses de l'Université Laval e Peeters Éditions de Leuven. Os historiadores, religiosos, acadêmicos, filólogos, linguistas e especialistas em literatura cristã primitiva e pesquisadores, cada um na sua diversidade de origem e em seu campo de especialização têm contribuído para a riqueza da

(c) Rev. Arqueologia Pública

Campinas, SP

v.9 No.(11) p. $43-57$ suplemento ISSN 2237-8294 
obra de um grupo inteiro. Neste ano de 2015 a descoberta dos Códices de Nag Hammadi completa-se 70 anos e para comerar, a Faculdade de Teologia e Ciências da Religião da Université Laval, em Quebec, no Canadá realizou no mês de maio passado um colóquio que reuniu diversos pesquisadores dos Códices de Nag Hammadi do mundo todo com o tema: Nag Hammadi à 70 ans. Qu'avons-nous appris? (Os 70 anos da descoberta de Nag Hammadi: o que aprendemos?

No Brasil, até onde foi possível pesquisar, não há muito avanço nos estudos dos Manuscritos da BCNH. O material que possuímos na sua maioria é de procedência de outros países, que por sua vez, limitam-se, de forma geral, a traduções. Porém, já temos insights com alguns artigos, algumas dissertações de mestrado e teses de doutorado. Alguns pesquisadores que já trabalham com esses documentos, como por exemplo Julio César Dias Chaves, que fez mestrado e doutorado em Ciências da Religião na Université Laval, Quebec, Canadá e que recentemente defendera sua tese doutoral e agora retorna ao Brasil.

\section{Contribuição da Biblioteca Copta de Nag Hammadi para o estudo do cristianismo}

A BCNH trouxe à luz muitas contribuições e uma diversidade até então não conhecida e hoje é de importância incalculável para a história dos livros, para a língua copta, para a história da filosofia antiga e para o estudo de manifestações marginais do cristianismo primitivo, pois com esta biblioteca abre-se uma nova janela sobre o período formativo do cristianismo por fornecerem: Tratados de teologia sistemática, obras exegéticas, epístolas, apocalipses, biografias e diários de viagem, relatos da paixão de Jesus apócrifos e códigos morais de várias fontes e inspirações. Certamente, eles apresentam ou trazem indícios de doutrinas e especulações que podem ser mais ou menos identificadas com as doutrinas e heresias eclesiásticas de escritores do II, III e IV séculos, estigmatizados como gnósticos.

Do ponto de vista histórico, a descoberta dessa biblioteca copta contribui para o aumento do conhecimento sobre como pensavam e escreviam esses grupos gnosticos ou não do II e III séculos da Era Cristã, de uma maneira diferente daquilo que se pode obter a partir do que os Pais da Igreja escreveram sobre eles. A história e compreensão do gnosticismo, tanto cristão, quanto não-cristão, se vê agora, a partir da descoberta de Nag Hammadi, totalmente ampliada e revista em muitos aspectos pelos pesquisadores. Através da

@ Rev. Arqueologia Pública

Campinas, SP

v.9 No.(11) p.43-57 suplemento ISSN 2237-8294 
descoberta de Nag Hammadi, portanto, pode-se entender melhor o gnosticismo e também perceber melhor como eram complexos os conflitos internos da igreja cristã primitiva no que diz respeito às suas doutrinas. Sem mencionar que os Códices de Nag Hammadi também trazem à tona o conteúdo de muitas obras gregas perdidas e que foram preservadas em tradução copta:

$\mathrm{Na}$ verdade, essa Biblioteca copta deve ser tomada como uma interpretação da existência, uma resposta para o dilema humano, uma atitude perante a sociedade e que merece ser levada a sério por qualquer pessoa capaz e disposta a abordar assuntos fundamentais. Essa postura básica tem sido vista até os dias de hoje quase que exclusivamente pela visão míope dos caçadores de heresia, que fazem referência apenas para refutá-la ou ridicularizá-la. Logo, o aparecimento da Biblioteca de Nag Hammadi nos oferece um acesso inesperado para a postura gnóstica como os próprios gnósticos a apresentavam. Ela é capaz de proporcionar novas raízes diante do que já foi desenraizado [2] (ROBINSON, 2006).

Do ponto de vista filosófico, a BCNH contribui também significativamente. Isto porque os escritos de Zostrianos, Allogenes, Protenóia Trimorfa e Marsanes, todos de orientação filosófica neoplatonista, nos dão informações sobre o neoplatonismo como era entendido naquela época. De modo que além de contribuir para a História das Religiões, com o estudo do gnosticismo, a BCNH também contribui para o estudo da História da Filosofia e para o estudo do Cristianismo, pois diante desta biblioteca, não se tem só o discurso de quem refutou, os eclesiásticos (os padres heresiólogos), mas também dos refutados tidos como heréticos. Daqueles que foram perseguidos e obrigados a abandonar ao grupo a que pertenciam e aos livros que liam.

Do ponto de vista geral, a BCNH possibilita o acesso a inúmeros escritos que auxiliam na reconstrução da evolução dos discursos e origens identitárias de nossa sociedade judaico cristã ocidental. A pesquisa desses códices, achados à margem leste do Nilo, no alto Egito em 1945 está longe de ser neutra. Por meio deles é possível perceber diversas experiências de fé e uma realidade de conflitos que resultaram no processo canônico da Bíblia, onde se impediu que certos ensinamentos e ideias fossem considerados parte da tradição cristã das primitivas

๔ Rev. Arqueologia Pública

Campinas, SP

v. 9 No.(11) p.43-57 suplemento ISSN 2237-8294 
comunidades. Estes possuem um caráter revolucionário, em especial por demonstrarem a existência de uma pluralidade de manifestações religiosas cristãs e não cristãs, quando ainda não existia um cânon e uma ortodoxia definidos.

\section{Referências Bibliográficas}

\section{Livros, Teses e dissertações}

ALMEIDA, Maria Aparecida de Andrade. Profeta e Luz: Categorias intercambiáveis para consolidar a identidade de Jesus na literatura joanina. São Bernardo do Campo: Universidade Metodista de São Paulo, 2013.Tese de Doutorado. Programa de pós-graduação em Literatura e Religião no Mundo Bíblico, Universidade Metodista de São Paulo, São Paulo, 2013.

AMADEU, Antero Luiz. Debate atual sobre o Gnosticismo: um olhar sobre o Jesus gnóstico de Nag Hammadi. São Bernardo do Campo: Universidade Metodista de São Paulo, 2010. Dissertação de Mestrado. Programa de pós-graduação em Literatura e Religião no Mundo Bíblico, Universidade Metodista de São Paulo, São Paulo, 2010.

CHAVES, Julio César Dias. A Gnose em Questão: Ensaios sobre Gnose e Apocaliptica na Antiguidade e a Biblioteca Copta de Nag Hammadi. Brasilia: 2011.

DORESSE, Jean. Les livres secrets des gnostiques d'Égypte. I. Introduction aux écrits gnostiques coptes découverts à Khénoboskion. Paris: Plon, 1958.

FUNARI, P. P. A., SILVA, Maria A. de O. (orgs.). Política e Identidades no MundoAntigo. São Paulo: FAPESP/Annablume, 2009.

IRINEU DE LYON. Contra as heresias. São Paulo: Paulus, 1995 (Col. Patrística, 4).

KING, Karen. What is Gnosticism? Cambridge: Harvard University Press, 2003.

LAYTON, Bentley. As escrituras gnósticas. Trad. Margarida Oliva. São Paulo: Edições Loyola, 2002.

POIRIER, Paul-Hubert; MAHĖ, Jean-Pierre (orgs.). Ecrits gnostiques: La bibliothèque de Nag Hammad. Paris: Gallimard, 2007.

ROBINSON, James M. (ed.). The Nag Hammadi Library in English. Nova York: Brill, 1996. . A Biblioteca de Nag Hammadi. São Paulo: Masdras, 2006. . The Coptic Gnostic Lybrary. Leinden/Boston: Brill, 2000.

\section{Revistas e Artigos}

CHAVES, Júlio César. A biblioteca copta de Nag Hammadi: uma história da pesquisa. In: Oracula 2.4 (2006): p 1-19.

( Rev. Arqueologia Pública

Campinas, SP

v.9 No.(11) p.43-57 suplemento ISSN 2237-8294 
PAGELS, Elaine. Ritual in the Gospel of Philip. In: John D. Turner e Anne McGuire (eds.). The Nag Hammadi Library after Fifty Years: Proceedings of the 1995 Society of Biblical Literature Commemoration. Leiden: Brill, 1997, p.280-291.

PAINCHAUD, Louis. L'Évangile selon Phillipe. In: Paul-Hubert Poirier e Jean-Pierre Mahé (eds.). Écrits gnostiques. Bibliothèque de la Pléiade. Paris: Gallimard, p.333-376.

PAINCHAUD, Louis. La classification des textes de Nag Hammadi et le phénomène des réécritures dans L. Painchaud et A. Pasquier (dir.). In: Les textes de Nag Hammadi et le problème de leur classification. Actes du colloque tenu à Québec du 15 au 19 septembre 1993, BCNH, section "Études", 3, Québec: Louvain et Paris, Presses de l'Université Laval et Peeters, 1995b, p. 51-85.

POIRIER, Paul-Hubert. La bibliothèque copte de Nag Hammadi: Sa nature et son importance. In: Sciences religieuses / Studies in Religion, 15. 1996, p. 303-316.

PUECH, Henri-Charles. Les nouveaux Écrits Gnostiques découverts en Haute-Égypte. In: Coptic studies in honor of Walter Ewing Crum. Boston: Byzantine Institute, 1950, p.100-110.

ROBINSON, James M. From Cliff to Cairo. The Story of the Discoverers and the Middlemen of the Nag Hammadi Codices in: Bernard Barc (ed.). Colloque international sur les textes Nag Hammadi. Québec: Université Laval, 1986. p. 21-58.

RODRIGUES, Elisa. As escrituras gnósticas e as origens cristãs. In: Revista Caminhando. V.

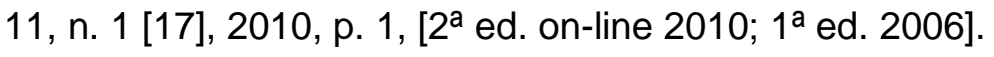

\section{Fontes eletrônicas}

http://www.oracula.com.br

http://www.naghammadi.org/publications/serie textes.aspx

http://www.naghammadi.org/traductions/traductions.aspx

๑ Rev. Arqueologia Pública

Campinas, SP

v.9 No.(11) 